\title{
Responses of isolated human basilar arteries to 5-hydroxytryptamine, noradrenaline, serum, platelets, and erythrocytes
}

\author{
LINDSEY M. STARLING, D. J. BOULLIN ${ }^{1}$, D. G. GRAHAME-SMITH, \\ C. B. T. ADAMS, AND R. S. GYE
}

From the M.R.C. Unit and Department of Clinical Pharmacology and Department of Neurological Surgery, Radcliffe Infirmary, Oxford

SYNOPSIS The isolated human basilar artery suspended in Krebs' solution contracts to 5-hydroxytryptamine, noradrenaline, and histamine, which stimulate specific receptors. Normal human serum contains an unidentified contractile substance, and erythrocytes relax the artery. Serum and erythrocytes potentiate 5 -HT contractions. This preparation is suitable for studying vasoactive sub- $\infty$ stances released during vasospasm after subarachnoid haemorrhage.

We are interested in studying the role of pharmacologically active agents in the aetiology of the prolonged vasospasm which is often associated with subarachnoid haemorrhage. There is some evidence for the involvement of 5-hydroxytryptamine (5-HT) and catecholamines in the development of vasospasm, but many workers believe that not all the causative agents have yet been identified (for review, see Echlin, 1968, 1971).

Previous experimental work has involved the use of animal models to simulate the human situation (Raynor et al., 1961; Echlin, 1965, 1968, 1971; Zervas et al., 1973). Also there have been a number of investigations of the pharmacological responses of both cerebral and peripheral arteries of animals (Bohr et al., 1961; Wilkins et al., 1967; Nielsen and Owman, 1971; Toda and Fujita, 1973; Allen et al., 1974a, b, c).

There do not appear to be any experiments with human cerebral arteries in vitro. Accordingly, we have investigated the responses of human basilar arteries, obtained at necropsy, to pharmacologically active agents relevant to subarachnoid haemorrhage, and to extracts of blood and tissues, because these are likely to be

\footnotetext{
1 Address for correspondence: D. J. Boullin, MRC Unit and Department of Clinical Pharmacology, Radcliffe Infirmary, Woodstock Road, Oxford OX2 6HE.

(Accepted 18 February 1975.)
}

the sources of the yet unidentified vasoactive agents.

\section{METHODS}

PREPARATION OF ARTERIES We obtained basilai arteries from 44 patients of either sex aged 23 to 86 years. Tissues were obtained at necropsy 22-90 hours after death and arteries with unequivocal signs of atheroma were discarded. Appropriate lengths of artery were dissected free of connective tissue and $\AA$ cut with alternate transverse sections as described by $\overrightarrow{\vec{O}}$ Vane (1957) for the rat fundus strip preparation. This left the helical musculature largely intact and forming a continuous strip. The arterial strip was mounted in a $13 \mathrm{ml}$ organ bath containing Krebs' bicarbonate solution of the following composition in $\mathrm{mmol} / \mathrm{l}: \mathrm{NaCl} 118.4 ; \mathrm{KCl} 4.7 ; \mathrm{MgSO}_{4} 7 \mathrm{H}_{2} \mathrm{O} 1.18$; $\mathrm{CaCl}_{2}$ 1.28; $\mathrm{KH}_{2} \mathrm{PO}_{4} 1.18 ; \mathrm{NaHCO}_{3} 25.0 ;$ glucose 11.1.

The Krebs' solution was gassed with $5 \%$ carbon $\frac{\circ}{3}$ dioxide in oxygen and maintained at a temperature of $37^{\circ} \mathrm{C}$. Approximately $0.75 \mathrm{~g}$ of tension was applied to the muscle and contractile responses $\frac{D}{0}$ recorded isotonically were displayed on a smoked drum. The magnification of the lever system was 20:1. N

All drug concentrations are expressed in terms of $N$ molalities of the base and represent the concentra- $N$ tion of drug present in the organ bath.

Blood collection Blood was collected from normale adult volunteers (aged 18-35 years) by venepuncture 
of the antecubital vein. The blood was either taken into a plastic container and allowed to clot at room temperature $\left(22^{\circ} \mathrm{C}\right)$ or into 0.11 volumes of $3.8 \%$ $(0.129 \mathrm{~mol} / \mathrm{l})$ sodium citrate.

SEPARATION OF SERUM, PLATELETS AND ERYTHROCYTES, AND PLASMA Serum was separated from clotted blood by centrifugation ( $3500 \mathrm{~g} / 10 \mathrm{~min}$ ) and then applied to the organ bath in volumes of 0.13 to $0.65 \mathrm{ml}$.

Platelets and erythrocytes were separated using citrated blood. Platelet rich plasma (PRP) was prepared by slow speed centrifugation as described by Boullin and O'Brien (1971) at $22^{\circ} \mathrm{C}$ instead of $4^{\circ} \mathrm{C}$. The supernatant PRP was removed and stored at room temperature (up to two hours). When required (see Results section) the platelets were disrupted by ultrasonic impulses provided by a Dawe Soniprobe, Type 7530-1A (Dawe Instruments Ltd, Concord Road, Western Avenue, London W3), fitted with an exponential titanium microtip, tuned to deliver $20000 \mathrm{~Hz}, 4.5 \mathrm{~A}$, using the procedure described by Ahtee et al. (1974).

The erythrocytes were precipitated by the above low speed centrifugation forming a lightly packed mass of cells in plasma and no further purification was made. $0.13-0.65 \mathrm{ml}$ aliquots of either intact cells or sonified cells (prepared as described for platelets) were applied to the organ bath. The haematocrits of these erythrocyte preparations were $55-65 \%$.

Cell free plasma was prepared by high speed centrifugation of PRP (3500 g/10 min) at $4^{\circ} \mathrm{C}$. $0.13-0.65 \mathrm{ml}$ of aliquots of the supernatant plasma were then applied to the organ bath as described in the Results section.

COLLECTION OF CSF CSF was collected from patients undergoing surgery for reasons other than subarachnoid haemorrhage. Up to $1.3 \mathrm{ml}$ of clear samples were applied to the organ bath and in some instances up to $11 \mathrm{ml}$ were freeze-dried and reconstituted in $1 \mathrm{ml}$ which was then tested on the artery.

PROCEDURE FOR APPLICATION OF DRUGS AND BLOOD Drugs were applied in volumes up to $0.65 \mathrm{ml}$ directly to the organ bath and left in contact with the basilar arteries for up to $30 \mathrm{~min}$. Thereafter the bath was emptied and the artery washed by refilling three times with Krebs' solution previously warmed to $37^{\circ} \mathrm{C}$.

\section{RESULTS}

RESPONSES TO DRUGS Approximately $50 \%$ of basilar arteries produced contractile responses to

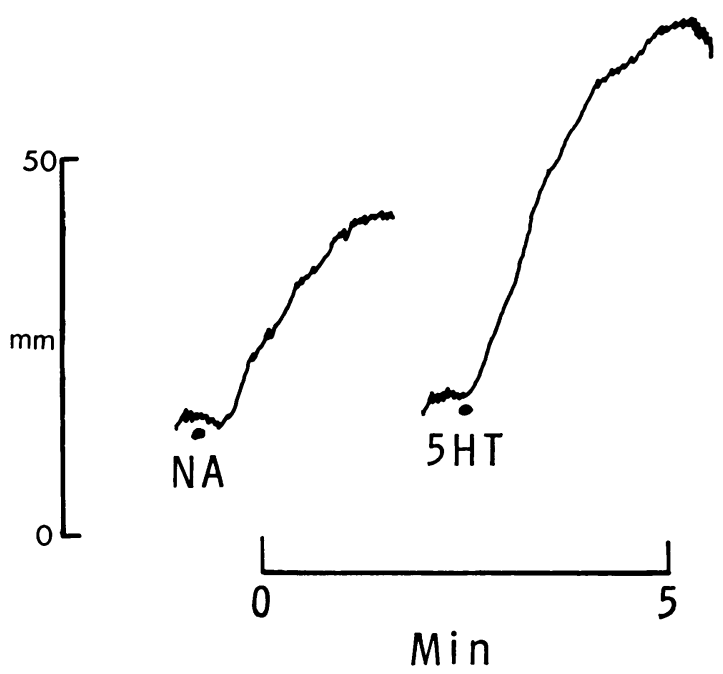

FIG. 1 Comparative responses of the human basilar artery to noradrenaline and 5-hydroxytryptamine. The arterial strip was mounted in a $13 \mathrm{ml}$ organ bath containing Krebs' bicarbonate solution at $37^{\circ} \mathrm{C}$, aerated with $95 \% \mathrm{O}_{2}, 5 \% \mathrm{CO}_{2}$, and approximately $0.75 \mathrm{~g}$ tension applied to the muscle. The responses were recorded isotonically on a smoked drum on a kymograph. Drugs were added at the filled circles. $10 \mathrm{nmol} / \mathrm{ml} \mathrm{NA} ; 1 \mathrm{nmol} / \mathrm{ml} \mathrm{5-HT}$.

5-HT (threshold concentration $0.1 \mu \mathrm{mol} / 1$ ); noradrenaline bitartrate (NA, $10 \mu \mathrm{mol} / \mathrm{l}$ ), and histamine dihydrochloride (H, $2 \mu \mathrm{mol} / \mathrm{l})$. Angiotensin, bradykinin, acetylcholine, and adrenaline were not tested.

Human basilar arteries were more sensitive to 5-HT than to NA (Fig. 1) in agreement with the work of Bohr et al. (1961), Nielsen and Owman (1971), and Toda and Fujita (1973) using arteries of various animal species. The threshold concentrations given above required to elicit contractions were 100 times lower for 5-HT than NA.

It was not possible to obtain dose response curves because of tachyphylaxis to 5-HT and NA. In most instances the arteries showed good contractions to drugs for at least three hours. When refrigerated overnight at $4^{\circ} \mathrm{C}$ and retested the next morning responses were often increased above those seen on the first day (Fig. 2 ), and it was often possible to study arterial responses for a total of 12-16 hours.

Use of pharmacological antagonists showed 


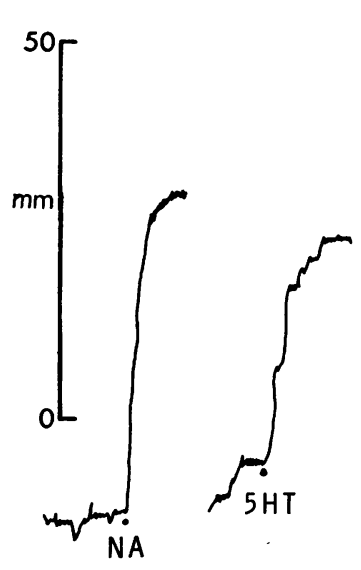

Day 1

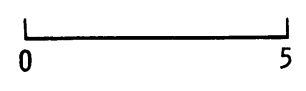

Min

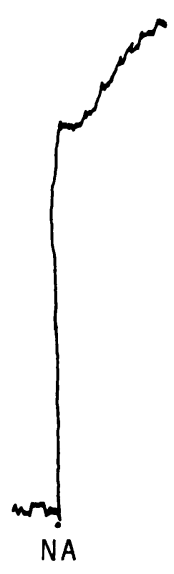

Day 2

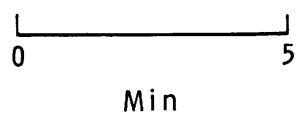

FIG. 2 Responses of human basilar artery to noradrenaline and 5-hydroxytryptamine before and after storage at $4^{\circ} \mathrm{C}$ for 18 hours. Experimental conditions as for Fig. 1. Drugs were added to the organ bath at the points shown. $20 \mathrm{nmol} / \mathrm{ml} \mathrm{NA;0.1} \mathrm{nmol/ml} \mathrm{5-HT}$.

that 5-HT, NA and $\mathrm{H}$ stimulated specific arterialo receptors. Thus contractions to 5-HT were blocked by $1 \mu \mathrm{mol} / 1$ 2-bromo-lysergic acid 0 diethylamide (BOL), leaving the responses to $\mathrm{NA}$ and $\mathrm{H}$ undiminished in the presence of this antagonist. Similarly, responses to NA were blocked by $1 \mu \mathrm{mol} / 1$ phentolamine (PHENT) and $\mathrm{H}$ by $1 \mu \mathrm{mol} / 1$ mepyramine maleate (MEP). Because of tachyphylaxis, investigation of the action of these blocking agents was difficult, therefore we used complete abolition of responses? as an index of specific antagonism rather than mere diminution of the response. There was now cross-tachyphylaxis to NA and 5-HT.

RESPONSES TO BLOOD We also tested each artery with blood drawn from normal volunteers of either sex (see Methods section). Where sodium $\omega_{\infty}^{\omega}$ citrate was used as an anticoagulant, appropriate $i$ control experiments involved the application of $0.13-0.65 \mathrm{ml}$ of $12.9 \mathrm{mmol} / 1$ sodium citrate in Krebs' solution to the $13 \mathrm{ml}$ organ bath. This was found not to contract or relax the basilare artery; on the other hand, application of thege

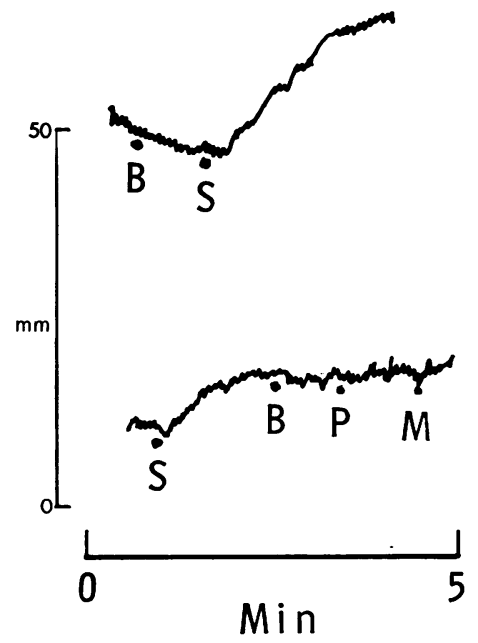

(a)

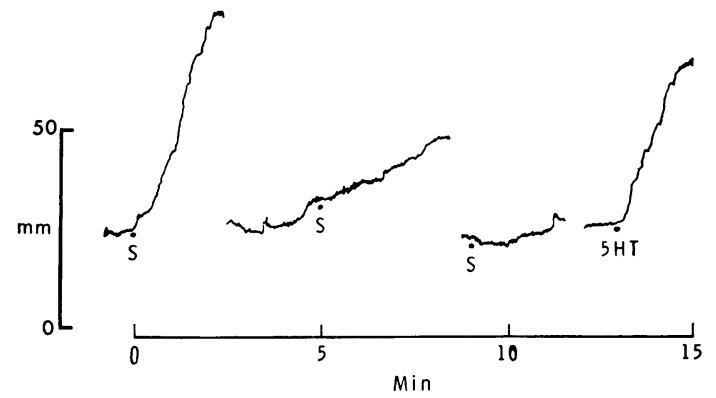

(b)

FIG. 3 Responses of the human basilar artery to normal serum $(0.65 \mathrm{ml})$ showing (a) the effect of blocking agents (BOL 1 umol/l, mepyramine maleate 1 umol/l, phentolamine 1 umolll; (b) tachyphylaxis to serum. Experimental conditions as for Fig. 1. (a) Upper record: application of the above blocking agents together at $\mathrm{B}$ before serum at $\mathrm{S}$. Lower record: application of serum at $\mathrm{S}$, followed by $\mathrm{BOL}$ at $\mathrm{B}$, phentolamine at $\mathrm{P}$, mepyramine at $\mathrm{M}$. (b) Serum was applied at $\mathrm{S}$, and $5-\mathrm{HT}(5 \mathrm{nmol} / \mathrm{l})$ at $5 \mathrm{HT}$. The organ bath was washed out three times between successive applications. 


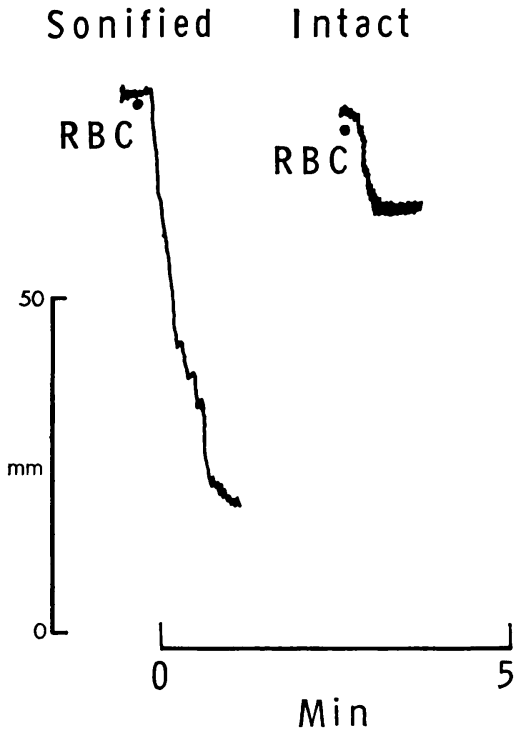

FIG. 4 Responses of the human basilar artery to sonified and intact erythrocytes (RBC) $(0.65 \mathrm{ml}$ cells in plasma) added to the organ bath at the circles. Experimental conditions as for Fig. 1.

volumes of serum to the organ bath produced arterial contractions in every instance where the tissues were also responsive to 5-HT and NA.

Contractions to serum developed within 30 seconds and, if allowed to remain in contact with the tissue, were sustained for up to 15 minutes. If the bath was washed after serum was applied for only three to five minutes, tachyphylaxis developed rapidly (Fig. 3b). Contractions were not abolished by BOL, phentolamine, and mepyramine maleate, added before or after the development of contractions (Fig. 3a).

These results therefore indicate the presence of an unidentified contractile substance in normal serum as described earlier by Wilkins $e t$ al. (1967).

In addition to examining serum, we also investigated the contractile effects of the blood cells and plasma. Provided the blood cells were removed, plasma did not contract the basilar artery in 21 out of 22 tests. In the instance where a contraction was seen, this was not sustained.

Sonified PRP contracted basilar arteries and the contractions were completely abolished by $1 \mu \mathrm{mol} / 1 \mathrm{BOL}$, showing that the responses were

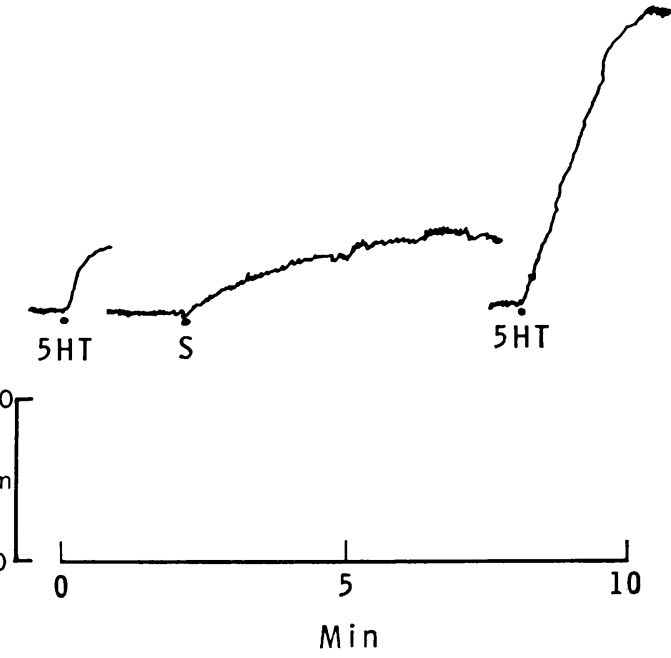

FIG. 5 Increased response of the human basilar artery to 5-hydroxytryptamine after contact with serum $(1.0 \mathrm{ml})$. Experimental conditions as in Fig. 1 . $20 \mathrm{nmol} / \mathrm{ml} \mathrm{5-HT}$ and $1.0 \mathrm{ml} \mathrm{serum}$ (S) were added at the filled circles. The bath was washed three times between doses, the drum being stopped for 10 minutes between applications.

entirely due to 5-HT. Zervas et al. (1973) have recently shown that 5-HT from platelets plays an important role in the production of vasospasm in canine basilar arteries in vivo.

The effects of intact and sonified erythrocytes were also studied. Both intact and sonified cells in plasma caused relaxation. In every case the response produced by sonified cells was more rapid and of greater magnitude than that produced by intact cells (Fig. 4). Intact and sonified cells also relaxed basilar arteries after contractions had been produced by normal serum (see Discussion). It is relevant that $\mathrm{K}^{+}$release from erythrocytes does not appear to be involved in this effect because $\mathrm{K}^{+}$contracts the artery (Toda and Fujita, 1973).

DRUG INTERACTIONS WITH SERUM AND TISSUES We found that when basilar arteries came into contact with serum, subsequent responses to 5-HT and NA were potentiated even after the serum was removed from the bath by washing three times (Fig. 5). This potentiation of drug induced contractions lasted for up to 15 minutes. 


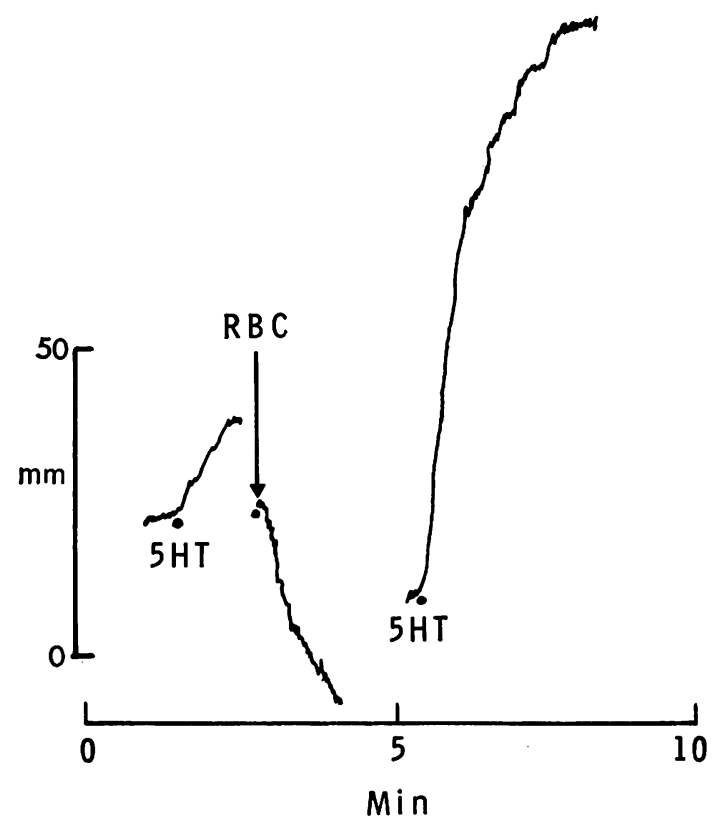

(a)

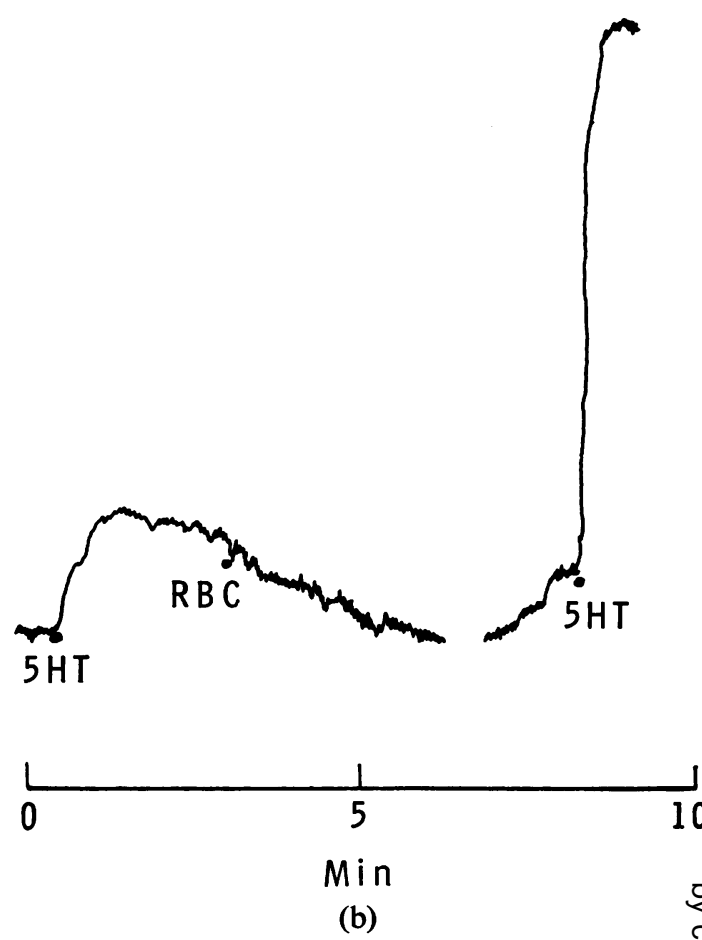

(b)

FIG. 6 Increased responses of the human basilar artery to 5-hydroxytryptamine after contact with (a) sonifieg and (b) intact erythrocytes. Experimental conditions as for Fig. 1. (a) $5-\mathrm{HT}$ (10 $\mathrm{nmol} / \mathrm{ml})$ applied at the circles; $0.65 \mathrm{ml}$ of sonified red cells were applied at RBC. The bath was washed three times between dose or (b) $5-H T(50 \mathrm{nmol} / \mathrm{ml})$ was applied at the circles; $0.65 \mathrm{ml}$ of intact red cells were applied at $R B C$. The bath was washed three times between doses.

A similar potentiation of 5-HT responses was also observed with both intact and sonified erythrocytes, in spite of the fact that the latter produced a relaxation (Figs $6 a$ and $b$ ).

Previous work had indicated that blood may interact with cerebral tissues to inhibit or destroy the unidentified blood borne contractile factor (Echlin, 1968, 1971). Accordingly, we examined the effects of clotted blood on brain tissue. Rat cerebral hemispheres were incubated with equal proportions of $(w / v)$ normal serum for 30 minutes at $37^{\circ} \mathrm{C}$ and then the fluid was tested on the basilar arteries. In six experiments there was no modification of the normal contractile response invariably observed with human serum. This showed that the factor was not inactivated by contact with rat brain (Fig. 7).

RESPONSES TO CSF Twelve basilar arteries failed to respond to normal CSF. There were no

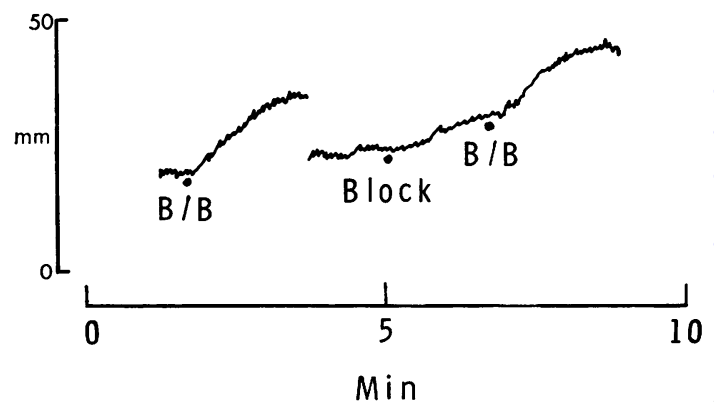

FIG. 7 Responses of the human basilar artery to $0.8 \mathrm{ml}$ serum previously incubated for 30 minutes with $\mathrm{N}$ rat cerebral hemispheres. BOL 1 umol/l, mepyramine maleate $1 \mu \mathrm{mol} / \mathrm{l}$, and phentolamine 1 umol/l were added to the organ bath at the filled circle marked 'block'. The serum from the blood and brain mixture was applied to the organ bath at the filled circles marked B/B. Experimental conditions as Fig. 1. 
changes in muscle tone and no evidence of either contraction or relaxation.

\section{DISCUSSION}

Our work shows that the human basilar artery can be used several days after death as a viable pharmacological preparation. We have confirmed several observations reported by others using cerebral arteries from several animal species in vitro and in vivo. First, the human artery is more sensitive to 5-HT than NA, in that the threshold concentration required to evoke a response is lower. This is in agreement with animal experiments (Bohr et al., 1961; Nielsen and Owman, 1971; Toda and Fujita, 1973). Also the amines seem to stimulate specific receptors on the human artery, because application of the appropriate antagonists leaves the response of the other amines undiminished.

Second, we confirm some recent observations of Allen et al. $(1974 \mathrm{a}, \mathrm{b}, \mathrm{c})$ of the contractile properties of normal human serum.

Allen et al. (1974b) obtained contractions with human serum using canine basilar arteries in vitro. The responses were partially blocked by $10 \mathrm{mmol} / \mathrm{l}$ phenoxybenzamine and, rather surprisingly, this was taken as evidence that the contractions were due to 5-HT. Further experiments in vivo (Allen et al., 1974c) failed to confirm the inhibitory effects of phenoxybenzamine. Previously, Echlin (1971) found that serum from monkeys did not contract the cerebral arteries of that species in situ.

In addition to responding to 5-HT, the muscle of the basilar artery also responds to contact with tissue extracts in different ways. The interactions between the effects of serum and contractions produced by $5-\mathrm{HT}$ or NA, appear to be one of our most important observations in relation to the aetiology of vasospasm.

The mechanism of these interactions appears to be of uncertain specificity and could involve complicated drug-receptor interactions or changes in the mechanisms for removal or inactivation of NA, 5-HT, and other unidentified substances.

The mechanisms of cerebral arterial spasm after subarachnoid haemorrhage are likely to be very complex. If it is assumed that the vasospasm is due to the synthesis and/or release of vaso- constrictor chemicals after interactions between blood, brain tissue, and cerebrospinal fluid, then our isolated arterial preparation is useful as an aid in the detection and identification of vasoactive substances. Thus our data showing that serum can enhance 5-HT induced basilar arterial constriction may reflect the modulating action of the amine upon vasoconstricting responses produced by other vasoactive compounds in situ.

After subarachnoid haemorrhage the cerebral arteries may well be more sensitive to these chemicals than normal. The results obtained so far are compatible with this view. We are proceeding to use the isolated human basilar artery for investigating the effects of material in the subarachnoid space obtained at operation from patients suffering from vasospasm associated with subarachnoid haemorrhage.

\section{REFERENCES}

Ahtee, L., Boullin, D. J., and Paasonen, M. K. (1974). Transport of taurine by normal human blood platelets. British Journal of Pharmacology, 52, 245-251.

Allen, G. S., Henderson, L. M., Chou, S. N., and French, L. A. (1974a). Cerebral arterial spasm. Part 1: In vitro contractile activity of vasoactive agents on canine basilar and middle cerebral arteries. Journal of Neurosurgery, 40, 433-441.

Allen, G. S., Henderson, L. M., Chou, S. N., and French, L. A. (1974b). Cerebral arterial spasm. Part 2: In vitro contractile activity of serotonin in human serum and CSF on the canine basilar artery, and its blockage by methylsergide and phenoxybenzamine. Journal of Neurosurgery, 40, 442-450.

Allen, G. S., Gold, L. H. A., Chou, S. N., and French, L. A. (1974c). Cerebral arterial spasm. Part 3: In vivo intracisternal production of spasm by serotonin and blood and its reversal by phenoxybenzamine. Journal of Neurosurgery, 40, 451-458.

Bohr, D. F., Goulet, P. L., and Taquini, A. C., Jr (1961). Direct tension recording from smooth muscle of resistance vessels from various organs. Angiology, 12, 478-485.

Boullin, D. J., and O'Brien, R. A. (1971). Abnormalities of 5-hydroxytryptamine uptake and binding by blood platelets from children with Down's syndrome. Journal of Physiology, 212, 287-297.

Echlin, F. A. (1965). Spasm of basilar and vertebral arteries caused by experimental subarachnoid hemorrhage. Journal of Neurosurgery, 23, 1-11.

Echlin, F. A. (1968). Current concepts in the etiology and treatment of vasospasm. Clinical Neurosurgery, 15, 133160.

Echlin, F. A. (1971). Experimental vasospasm, acute and chronic, due to blood in the subarachnoid space. Journal of Neurosurgery, 35, 646-656.

Nielsen, K. C., and Owman, C. (1971). Contractile response and amine receptor mechanisms in isolated middle cerebral artery of the cat. Brain Research, 27, 33-42. 
Raynor, B. B., McMurtry, J. G., and Pool, J. L. (1961). Cerebrovascular effects of topically applied serotonin in the cat. Neurology (Minneap.), 11, 190-195.

Toda, N., and Fujita, Y. (1973). Responsiveness of isolated cerebral and peripheral arteries to serotonin, norepinephrine, and transmural electrical stimulation. Circulation Research, 33, 98-104.

Vane, J. R (1957). A sensitive method for the assay of 5-hydroxytryptamine. British Journal of Pharmacology and Chemotherapy, 12, 344-349.

Wilkins, R. H., Wilkins, G. K., Gunnells, J. C., and Odom, G. L. (1967). Experimental studies of intracranial arterial $T$ spasm using aortic strip assays. Journal of Neurosurgery, of 27, 490-500.

Zervas, N. T., Kuwayama, A., Rosoff, C. B., and Salzman, E. W. (1973). Cerebral arterial spasm. Modification by inhibition of platelet function. Archives of Neurology, 28, 400-404. 